
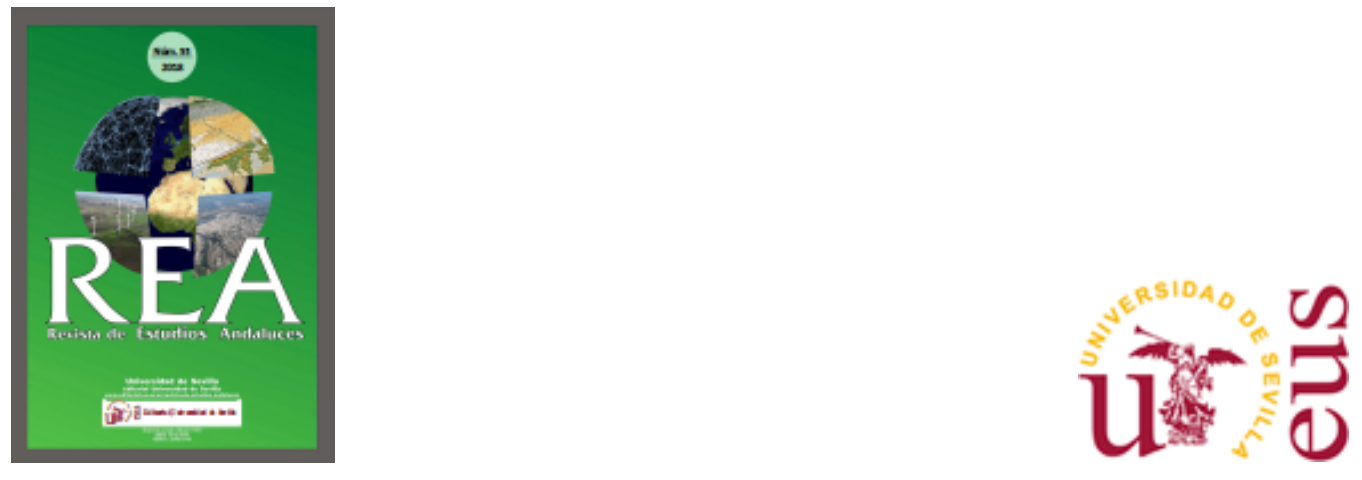

Revista de Estudios Andaluces (REA)

e-ISSN: $2340-2776$.

REA núm. 35 (2018). http://dx.doi.org/10.12795/rea.2018.i35

Las Rutas e Itinerarios Turístico-Culturales en los Portales Oficiales de Turismo de las Comunidades Autónomas Españolas

Tourist-Cultural Routes and Itineraries in the Official Tourism Portals of the Spanish Autonomous Communities

\author{
Diego Manuel Calderón-Puerta \\ Universidad de Cádiz \\ diego.calderonpu@alum.uca.es \\ Manuel Luis Arcila-Garrido \\ Universidad de Cádiz \\ manuel.arcila@uca.es \\ José Antonio López-Sánchez \\ Universidad de Cádiz \\ joseantonio.lopez@uca.es
}

Formato de cita / Citation: Calderón-Puerta, Diego Manuel; Arcila-Garrido, Manuel Luis; López-Sánchez, José Antonio (2018). Las Rutas e Itinerarios Turístico-Culturales en los Portales Oficiales de Turismo de las Comunidades Autónomas Españolas. Revista de Estudios Andaluces, núm. 35, 123-145. http:// dx.doi.org/10.12795/rea.2018.i35.05

Enlace artículo/to link to this article: http://dx.doi.org/10.12795/rea.2018.i35.05

c) (7) (8)

Esta obra se distribuye con la licencia Creative Commons Reconocimiento-NoComercial-

SinObraDerivada 4.0 Internacional

http://editorial.us.es/es/revista-de-estudios-andaluces

https://revistascientificas.us.es/index.php/REA 


\title{
Las Rutas e Itinerarios Turístico-Culturales en los Portales Oficiales de Turismo de las Comunidades Autónomas Españolas
}

\section{Tourist-Cultural Routes and Itineraries in the Official Tourism Portals of the Spanish Autonomous Communities}

\author{
Diego Manuel Calderón-Puerta \\ Universidad de Cádiz \\ diego.calderonpu@alum.uca.es \\ Manuel Luis Arcila-Garrido \\ Universidad de Cádiz \\ manuel.arcila@uca.es \\ José Antonio López-Sánchez \\ Universidad de Cádiz \\ joseantonio.lopez@uca.es
}

Recibido: 8 de enero, 2018

Revisado: 23 de enero, 2018

Aceptado: 25 de enero, 2018

\section{Resumen}

El turismo cultural se ha convertido en las últimas décadas en una alternativa a otras tipologías turísticas, puesto que es necesaria una oferta más complementaria. Esta expansión de la cultura como producto turístico ha propiciado la proliferación de rutas e itinerarios turístico-culturales, potenciados por organismos regionales, nacionales e internacionales. Estas realidades turísticas han generado multitud de definiciones por parte de organismos y autores, dando pie a un debate sobre dos conceptos que, aunque comparten similitudes, pueden considerarse diferentes. En la difusión, creación y reconocimiento de rutas e itinerarios juegan un papel fundamental los diferentes gobiernos autonómicos españoles. En este sentido mediante la creación de páginas web oficiales, las Comunidades Autónomas tratan de dar a conocer su cultura y sus productos turísticos. Por un lado, el objetivo de este trabajo es analizar los conceptos de ruta e itinerario turístico cultural, y por otro lado se estudiará la difusión de las rutas turísticas y el tratamiento de los itinerarios por parte de las Comunidades Autónomas en sus portales oficiales.

Palabras clave: Ruta turística, itinerario cultural, Comunidades Autónomas, portal. 


\begin{abstract}
In the last decades, cultural tourism has become an alternative to other tourist typologies, since a more complementary offer is necessary. This expansion of culture as a tourism product has led to the proliferation of routes and tourist-cultural itineraries, promoted by regional, national and international organizations. These tourist realities have generated a multitude of definitions by organisms and authors, giving rise to a debate on two concepts that although they share similarities can be considered different. In the diffusion, creation and recognition of routes and itineraries, the different Spanish autonomous governments play a fundamental role. In this sense, through the creation of official websites, the Autonomous Communities try to publicize their culture and their tourism products. On the one hand, the objective of this work is to analyze the concepts of cultural tourism route and itinerary, on the other hand the dissemination of tourist routes and the treatment of itineraries by the Autonomous Communities in their official portals will be studied.
\end{abstract}

Key Words: Tourist route, cultural itinerary, Autonomous Communities, portal. 


\section{INTRODUCCIÓN}

En los últimos años hemos asistido a una importante proliferación de rutas turísticas y al reconocimiento de itinerarios culturales que, en muchos casos, han sido utilizados desde el punto de vista turístico.

La expansión de las rutas e itinerarios culturales como productos turísticos ha suscitado el interés de distintos autores e instituciones, tanto nacionales como internacionales, por su estudio y definición. En este sentido, se ha ido elaborando un marco teórico (Parrado del Olmo, 2003; López, 2006; Moreré, 2009; Hernández, 2011; Navalón, 2014) que ha incorporado propuestas de definiciones que han pretendido dotar de contenido a estos dos conceptos. Estas propuestas han sido objeto de estudio debido a la confusión terminológica entre los mismos. De este modo mientras algunos autores defienden su similitud (Parrado del Olmo, 2003), otros sostienen que son realidades diferentes (Hernández, 2009).

El principal objetivo de este trabajo es analizar el concepto de ruta e itinerario cultural. Por otro lado, también se estudiará el tratamiento que ambos conceptos tienen en la oferta de rutas e itinerarios culturales realizada por las entidades o instituciones de promoción turística de las Comunidades Autónomas españolas.

Para alcanzar estos objetivos utilizaremos una metodología consistente en el análisis de la literatura existente sobre el estado de la cuestión y la interpretación de documentos institucionales, tanto nacionales como internacionales, de los organismos competentes en la materia. De este modo se pretende alcanzar una definición de síntesis de los conceptos objeto de estudio. La siguiente fase plantea obtener mediante el uso de una búsqueda sistemática y estructurada en las páginas webs de promoción turística oficiales de las CCAA, una visión detallada del uso de los conceptos objeto de estudio en la oferta de productos turísticos.

\section{LA CULTURA COMO RECURSO TURISTICO}

Cuando analizamos el turismo y la cultura tenemos que tener presente que son dos términos interdependientes. El concepto de cultura tiene su origen en la expresión latina "cultura animi", utilizado por vez primera en la obra "Tusculanae Disputation" de Cicerón, cuya raíz latina era "cultura", que a su vez deriva de la voz "colere", que hacía referencia al cuidado del campo o del ganado (García, 2001).

Desde sus inicios la actividad turística ha tenido un componente cultural importante. En este sentido podemos citar a modo de ejemplo, el Grand tour que realizaban los jóvenes ingleses tras finalizar sus estudios a finales del siglo XVI. Ya en el siglo XIX la revolución industrial y los avances científico-técnicos, posibilitaron que los viajeros visitaran nuevos lugares (Egipto, Grecia etc.) y que surgieran propuestas de viajes como las de Thomas Cook (Correyero, 2008).

Revista de Estudios Andaluces, núm. 35 (2018) pp. 123-145. e-ISSN: 2340-2776 http://dx.doi.org/10.12795/rea.2018.i35.05 
El desarrollo generalizado de la cultura como recurso turístico tiene sus orígenes en la década de 1960, cuando se toma una mayor conciencia en Europa del patrimonio como fuente de conocimiento y disfrute (Tresserras, 2001). Basada en esta nueva interpretación del patrimonio, con la Carta de Venecia de 1965 y la convención de 1972 de la UNESCO, comienza la andadura institucional del turismo cultural, proporcionándose una definición que lo concibe como" "aquellas formas de turismo que tienen por objeto, entre otros fines, el conocimiento de monumentos y sitios histórico-artísticos." (ICOMOS, 1976: 238.). Esta primera interpretación pone de manifiesto el reducido campo de actuación que en principio tiene el turismo cultural, puesto que se obvian otras manifestaciones culturales como puede ser la gastronomía, las tradiciones etc.

Conforme esta nueva visión del turismo cultural se va consolidando, el concepto va evolucionando y concretándose con definiciones como la formulada en 1985 por la OMT en la que el turismo cultural recoge "todos los movimientos de las personas para satisfacer la necesidad humana de diversidad, orientados a elevar el nivel cultural del individuo, facilitando nuevos conocimientos y experiencias" y la posterior definición de ICOMOS, en $1999^{2}$, en la que esta tipología turística "Abarca los paisajes, los sitios históricos, los emplazamientos y entornos construidos, así como la biodiversidad, los grupos de objetos diversos, las tradiciones pasadas y presentes, y los conocimientos y experiencias vitales". En este mismo texto se defiende que el turismo cultural "registra y expresa largos procesos de evolución histórica, constituyendo la esencia de muy diversas identidades nacionales, regionales, locales, indígenas y es parte integrante de la vida moderna".

Atendiendo a las diferentes definiciones, el turismo cultural consiste en el uso turístico de elementos patrimoniales, pero también incluye todas aquellas producciones culturales perpetuadas en la sociedad a lo largo del tiempo (Tondre, 2007). Es interesante destacar como la OMT resalta esta tipología turística como una adquisición de conocimiento y la vivencia de una experiencia. Este interés por entender o identificarse con elementos culturales propios o ajenos es lo que proporciona un valor añadido al turismo cultural y lo diferencia de otras formas de hacer turismo (Orduña, 2010).

El desarrollo del turismo cultural responde, por lo tanto, al "deseo de conocer y comprender; consumo de un producto que incluya un significado cultural; y la

\footnotetext{
1 Carta de ICOMOS adoptada en Bruselas en 1976. Recuperado de http://ipce.mecd.gob.es/dam/jcr:7bec1917-8752-4444-ab46-d7e0add3edad/1976-carta-turismocultural-bruselas.pdf (22/01/2018).

2 Carta Internacional sobre Turismo Cultural. 1999. Recuperado de http://www.iaph.es/export /sites/default/galerias/patrimonio-cultural/documentos/gestion-informacion/ icomoscartainternacional sobreturismocultural.pdf (22/01/2018).
}

Revista de Estudios Andaluces, núm. 35 (2018) pp. 123-145. e-ISSN: 2340-2776 http://dx.doi.org/10.12795/rea.2018.i35.05 c) $($ ) $(9)$ 
intervención de un mediador que subraya el valor cultural del producto, lo presenta y explica" (Navalón, 2014). La cultura para el sector turístico representa una forma de turismo sostenible, en el que el turista se caracteriza por su alto nivel económico y cultural. Además, posibilita el desarrollo de zonas deprimidas, pone fin a la estacionalidad, fomenta el empleo y permite la puesta en valor del patrimonio, tradiciones y costumbres de una región (Pulido, 2013).

De este modo la confección de rutas y la declaración de itinerarios deben contener según Herbert (2001) unos objetivos claros que expliquen la finalidad de las mismas, sus elementos diferenciadores y un posterior estudio sobre su aceptación tras su puesta en marcha, que incluya los aspectos de mejora señalados por los usuarios.

El diseño de una ruta turística y el reconocimiento de los itinerarios culturales pretende intervenir en el sector turístico de manera que, mediante la oferta de un producto de calidad, se aumenten los beneficios y se diversifique la oferta turística de una determinada región.

\section{RUTAS E ITINERARIOS CULTURALES: ANÁLISIS CONCEPTUAL}

Es frecuente que los conceptos de ruta e itinerarios turísticos culturales se confundan, aunque existan notables diferencias entre ambas realidades. Se puede establecer que dicha confusión se produce a partir de la década de 1990, cuando los itinerarios comienzan a ser reconocidos y se hace hincapié en conocer los elementos diferenciadores entre las rutas y los itinerarios culturales. Es, por lo tanto, necesario analizar las definiciones disponibles, así como ofrecer una reflexión sobre los elementos diferenciadores de ambos conceptos.

Para aproximarse al concepto de ruta e itinerario conviene hacer referencia en primer lugar a la definición de la Real Academia Española (R.A.E) según la cual una ruta es la "Rota o derrota de un viaje. Itinerario para él. Camino que se toma". Por otro lado, la R.A.E entiende como itinerario a la "Ruta que se sigue para llegar a un lugar".

La propia lectura de las definiciones pone de manifiesto la dificultad de su aplicación al ámbito turístico, puesto que ruta e itinerario se nos presentan como conceptos similares. El análisis filológico de la R.A.E. ha servido como punto de partida para que algunos estudios (Parrado del Olmo, 2003) hayan planteado que rutas e itinerarios culturales son términos sinónimos. Las razones para llegar a esta conclusión residen en el hecho de que tanto rutas como itinerarios se desarrollan a lo largo de un trazado, es decir, basado en la realidad física de los mismos. A pesar de que tanto ruta como itinerario tienen un recorrido que sirve como nexo de conexión entre uno o varios elementos, existe un aspecto diferenciador que se manifiesta en la propia configuración de ambas realidades. Por un lado, la ruta implica un desplazamiento en el que la persona dispone de amplias facultades para establecer el recorrido del mismo en base a sus intereses. Por tanto, las rutas tienen un carácter instrumental, que en

Revista de Estudios Andaluces, núm. 35 (2018) pp. 123-145. e-ISSN: 2340-2776 http://dx.doi.org/10.12795/rea.2018.i35.05 
turismo se refleja en la creación de un producto que conecta una temática con el patrimonio y el territorio (Martorell, 2017). En lo que respecta al itinerario, el aspecto físico adquiere un mayor protagonismo, puesto que el trazado atenderá a una necesidad perpetuada en el tiempo (religiosa, militar, comercial etc.), dejando poco margen a la capacidad humana para definir su recorrido (Castillo, 2006). Entendemos, por lo tanto, que en la estructuración de las rutas e itinerarios la diferencia reside en el aspecto subjetivo de las primeras (voluntad humana) en contraposición al elemento objetivo de las segundas (espacio geográfico).

Para reforzar la idea aquí defendida, es necesario analizar algunas definiciones de rutas turísticas e itinerarios turísticos enunciados por organismos, instituciones y autores. Desde la toma de conciencia de la cultura como producto turístico han sido numerosas las propuestas conceptuales que se aproximan a esta temática, no obstante, en la actualidad no hay una definición comúnmente aceptada de ruta turística. De entre todas las definiciones una de las más interesantes es la propuesta por Chan (1996) que las analiza como "una propuesta estandarizada de lugares y actividades a realizar en una zona bajo régimen, tiempos y duración de visitas flexibles. Son una modalidad de productos turísticos que basado en un recorrido previo facilita la orientación del pasajero en el destino"

En este mismo orden de ideas Hernández Ramírez (2011) entiende las rutas como productos turísticos clasificados en función a las que "invitan al visitante a recorrer un periplo en el que predomina una determinada categoría patrimonial, ya sean manifestaciones culturales, testimonios del pasado arqueológico o histórico, patrimonio artístico, industrial o espacios naturales" (pp.227). También este autor las define como propuestas que "recrean el territorio a través de nuevos atractivos que poco o nada tienen que ver con la realidad histórica y cultural de los destinos, pero que se incorporan como valores añadidos a los mismos" y por último, como creaciones mixtas "en las que, siguiendo determinadas propuestas del marketing, el producto turístico se forma a partir de la suma de varios componentes, los cuales son prescindibles y sustituibles por otros" (pp. 228).

Las definiciones estudiadas ponen de manifiesto el uso de conceptos tales como "propuesta", "productos turísticos" o "marketing" que evidencian el carácter intencionado de la creación de las rutas turísticas, y que se presentan como una herramienta moldeable en función a los intereses de la oferta y demanda turística.

Por su parte, en lo que respecta al itinerario cultural como elemento turístico, dicho concepto ha estado ausente de la bibliografía y de la propia convención del patrimonio mundial hasta el año 1994. Es a partir de esta fecha y fundamentalmente desde 1998 cuando tiene un mayor uso, ya que asistimos a la creación del comité internacional de itinerarios culturales (Vidargas, 2011). Previamente se había producido la declaración del Camino de Santiago ruta histórica en 1987, mientras que, a escala europea, surge el Instituto Europeo de itinerarios culturales en 1998. En todo este proceso se puede

Revista de Estudios Andaluces, núm. 35 (2018) pp. 123-145. e-ISSN: 2340-2776 http://dx.doi.org/10.12795/rea.2018.i35.05 
apreciar un creciente interés por parte de las instituciones por el reconocimiento y puesta en valor de los itinerarios culturales.

Los primeros intentos para definir los itinerarios culturales se producen en 1994 en la reunión de expertos del ICOMOS. En la misma se considera que el itinerario cultural no es sólo la suma de elementos diversos (pueblo, paisajes culturales, sitios), sino que realmente incorpora el espíritu intangible e histórico que une a estos elementos en un todo ${ }^{3}$.

Estas apreciaciones servirán de base para que en la posterior definición ofrecida por ICOMOS en la declaración de 2004, se sistematicen los itinerarios en función del contexto, el contenido, el valor y el dinamismo de los mismos (Torres, 2006).

Estos primeros intentos, aunque todavía alejados de una especificación más exhaustiva, ponen de manifiesto la toma de conciencia por parte de las instituciones de cara a entender cómo se configuran los itinerarios y los elementos que intervienen en ese proceso. Con posterioridad las instituciones y organismos han ido concretando sus definiciones sobre itinerarios, siendo las propuestas más interesantes las ofrecidas por el Consejo de Europa en 2002, la de ICOMOS en 2008 y MERCOSUR en 2009.

La primera de ellas entiende como itinerario cultural europeo" "un recorrido que abarca uno o varios países o regiones, y que se organiza alrededor de los temas cuyo interés histórico, artístico o social se revela como europeo, sea en función del trazado geográfico del itinerario, sea en función de su contenido y de su significación." (Consejo de Europa, 2002).

Por su parte, ICOMOS se refiere a los itinerarios culturales como "Toda vía de comunicación terrestre, acuática o de otro tipo, físicamente determinada y caracterizada por poseer su propia y específica dinámica y funcionalidad histórica al servicio de un fin concreto y determinado, que reúna las siguientes condiciones: a) Ser resultado y reflejo de movimientos interactivos de personas, así como de intercambios multidimensionales, continuos y recíprocos de bienes, ideas, conocimientos y valores entre pueblos, países, regiones o continentes, a lo largo de considerables períodos de tiempo; b) haber generado una fecundación múltiple y recíproca, en el espacio y en el tiempo, de las culturas afectadas que se manifiesta tanto en su patrimonio tangible como intangible; y c) haber integrado en un sistema dinámico las relaciones históricas y los bienes culturales asociados a su existencia." (ICOMOS, 2008).

\footnotetext{
3 ICOMOS CIIC Scientific Meeting-Madrid (2002): "The conceptual and substantive Independence of cultural routes in relation to cultural landscapes", considerations and recommendation submitted to the ICOMOS 13 th.General Assembly at its plenary session held on 5/12/2002.

4 Programa de los Itinerarios Culturales Europeos. Recuperado de https://www.mecd.gob.es/dam/ jcr:590c8c17-0eb5-48ba-b47f-5d42b5206dbd/itinerarios-culturales.pdf (22/01/2018).

${ }^{5}$ ICOMOS. Carta de Itinerarios Culturales. 2008
}

Revista de Estudios Andaluces, núm. 35 (2018) pp. 123-145. e-ISSN: 2340-2776 http://dx.doi.org/10.12795/rea.2018.i35.05 
Por último, para MERCOSUR el itinerario cultural hace referencia a caminos "que a lo largo del tiempo ejercieron su influencia cultural mediante la transculturación, y que produjeron otros medios de expresión diversos a los que en un origen existieron en cada lugar." (MERCOSUR, 2009).

En las definiciones ofrecida por ICOMOS y MERCOSUR se observa que se pone mayor énfasis en resaltar el interés por el trazado como eje integrador de todos los elementos del itinerario y, por lo tanto, como valor patrimonial intrínseco. Por su parte el concepto de itinerario cultural europeo pretende destacar el carácter europeo de los itinerarios, como elemento de cohesión e identidad cultural, pasando a un segundo plano la concepción turística del itinerario (Tendré, 2007).

Tomando como puntos de referencia las definiciones y aportaciones realizadas por autores y organismos, debe entenderse que las rutas e itinerarios son conceptos que, aun compartiendo elementos comunes, son realidades diferentes, aunque complementarias. Así, según Hernández (2011) "no pueden confundirse los itinerarios culturales con las rutas turístico-culturales, porque los primeros responden a criterios históricos de autenticidad, de continuidad y de intercambios contrastados entre culturas, mientras que las segundas son invenciones turísticas de conveniencia, promovidas por agentes públicos o privados, que unen recursos patrimoniales más o menos homogéneos y vinculados entre sí" (pp.231).

En este sentido, desde nuestro punto de vista se pueden conceptualizar las rutas como un elemento esencialmente turístico, es decir, un producto confeccionado utilizando los recursos territoriales. La ruta es una invención siendo lo importante en ella no tanto el recorrido, el cual está creado con un interés turístico, sino el patrimonio natural, histórico, etnográfico, geográfico etc, que la compone y justifica.

Por su parte, entendemos que el itinerario cultural es un recorrido desarrollado a lo largo del tiempo y que responde a necesidades humanas. La puesta en valor del itinerario es el propio recorrido y no tanto los elementos que lo integran, aunque estos últimos sean un factor que permitan entender el porqué de la existencia del itinerario. Debemos tener en cuenta además que cuando un itinerario cultural es potenciado desde el punto de vista turístico recibe el nombre de itinerario turístico cultural. Esta terminología nos da a entender que no todos los itinerarios son susceptibles de utilidad turística puesto que la misma dependerá de las características del itinerario, el interés que provoque y las posibilidades de desarrollo que genere.

Por lo tanto, puede concluirse que tanto ruta como itinerario son conceptos con bastantes similitudes pero que se diferencian en la intencionalidad de su creación, su

\footnotetext{
${ }^{6}$ Mercosur (2009). Anteproyecto de itinerarios culturales del Mercosur. San Salvador Bahía (Brasil) en www.unesco.org.uy/ci/fileadmin/cultura/Misiones/Anteproyecto_Itinerarios_Cult_MERCOSUR.pdf (22/01/2018).
}

Revista de Estudios Andaluces, núm. 35 (2018) pp. 123-145. e-ISSN: 2340-2776 http://dx.doi.org/10.12795/rea.2018.i35.05 
Tabla 1: Cuadro con diferencias y similitudes entre ruta turística e itinerario cultural.

\begin{tabular}{|c|c|c|}
\hline Elementos & Rutas Turísticas & Itinerarios culturales \\
\hline Origen & $\begin{array}{l}\text { Invención de un producto } \\
\text { turístico para su } \\
\text { comercialización. }\end{array}$ & $\begin{array}{l}\text { Trayecto que históricamente } \\
\text { atiende a necesidades sociales, } \\
\text { económicas, militares, religiosas } \\
\text { etc. (López Fernández, 2006). }\end{array}$ \\
\hline Finalidad & $\begin{array}{c}\text { Cohesionar elementos } \\
\text { culturales relacionados con } \\
\text { una temática para su uso } \\
\text { turístico. }\end{array}$ & $\begin{array}{l}\text { Atender a las necesidades } \\
\text { humanas perpetuadas en el } \\
\text { tiempo. En el caso de los } \\
\text { itinerarios culturales europeos, } \\
\text { consolidar la identidad europea. }\end{array}$ \\
\hline Valor Patrimonial & $\begin{array}{l}\text { El recorrido carece de valor } \\
\text { patrimonial, lo importante son } \\
\text { los hitos seleccionados a los } \\
\text { que el recorrido pone en } \\
\text { relación en base a un elemento } \\
\text { o elementos comunes. }\end{array}$ & $\begin{array}{c}\text { El recorrido tiene valor } \\
\text { patrimonial, al igual que los } \\
\text { elementos que lo conforman. }\end{array}$ \\
\hline Uso turístico & $\begin{array}{c}\text { Proliferación de rutas } \\
\text { potenciadas por organismos } \\
\text { públicos y privados. }\end{array}$ & $\begin{array}{l}\text { Reconocimiento institucional de } \\
\text { las vías históricas. No todos los } \\
\text { itinerarios tienen un uso turístico. }\end{array}$ \\
\hline Creación & $\begin{array}{l}\text { Libertad para decidir sobre los } \\
\text { hitos, temática y recorrido. }\end{array}$ & $\begin{array}{l}\text { Imposibilidad de decidir la } \\
\text { trayectoria y los hitos. Su puesta } \\
\text { en valor consiste en realzar el } \\
\text { sentido y el valor cultural del } \\
\text { recorrido. }\end{array}$ \\
\hline
\end{tabular}

Fuente: Elaboración propia a partir del estudio de los trabajos y declaraciones sobre la temática.

uso y la finalidad de los mismos (Tabla 1).

\section{ORIGEN DE LAS RUTAS Y MARCO COMPETENCIAL DE LAS CCAA.}

El turismo en España desde el punto de vista institucional comienza su andadura en 1905, con el Real Decreto de 6 de octubre de 1905, por el cual nace la Comisión Nacional del Turismo. Con posterioridad, la Comisaría Regia de Turismo y el Patronato Nacional de Turismo, fomentarían esta modalidad cultural y de ocio como una fuente de riqueza y puesta en valor de los recursos nacionales (Moreno, 2001).

Los primeros intentos de creación de rutas turísticas en España los encontramos durante la década de 1930, con las llamadas "Rutas de la guerra". No obstante, su funcionalidad turística era muy limitada y tenían un valor esencialmente propagandístico (Correyero, 2001). Durante las décadas de 1940 y 1950 el turismo español permanecerá estancado debido a la autarquía y al aislamiento internacional, tomando impulso con el I Plan de Desarrollo de 1963.

La proliferación de rutas turísticas en nuestro país, al igual que en el resto de Europa, tienen su eclosión en la década de 1960. En la cual, bajo el impulso del desarrollo

Revista de Estudios Andaluces, núm. 35 (2018) pp. 123-145. e-ISSN: 2340-2776

http://dx.doi.org/10.12795/rea.2018.i35.05 (c) (i) (3) 
turístico e industrial español desde las instituciones, se publica el "Noticiario Turístico" y se crean la ruta de Don Quijote (1966), la ruta del Cid (1967), el Camino de la Plata (1968), rutas de Bécquer y el Camino de Santiago (1970) (Morère, 2012).

Por su parte, tal y como se ha explicado anteriormente, la aparición de itinerarios culturales se produce en la década de 1990, en los que el interés de las instituciones por los mismos se manifiesta tanto en los congresos de ICOMOS de 2002 y 2006 como en la elaboración de la Carta de Itinerarios Culturales en 2008.

No obstante, a pesar del impulso en la oferta de rutas y el uso turístico de algunos itinerarios, la especialización de España en el modelo turístico de sol y playa ha propiciado que estos productos hayan tenido un papel secundario hasta tiempos recientes, en los que, dados los beneficios del turismo cultural, las instituciones y organismos, tanto públicos como privados, promocionan y crean nuevas rutas, a la vez que se declaran los itinerarios culturales.

A escala regional los organismos competentes en la promoción del turismo son los gobiernos autonómicos. Las comunidades autónomas, conforme a lo dispuesto en la Constitución de 1978, deben realizar la "promoción y ordenación del turismo dentro de su ámbito territorial” (Art. 148.1.18a ). En este sentido, gracias a la transferencia de competencias en materia de turismo por parte del gobierno central a las CCAA (Parada, 2013), las distintas instituciones autonómicas han elaborado y fomentado las rutas turísticas y los itinerarios mediante publicaciones, páginas web, creación de equipamientos y señalética.

\section{EL USO DE LOS CONCEPTOS DE RUTAS E ITINERARIOS TURÍSTICO-CULTURALES, EN LAS WEBS OFICIALES DE TURISMO DE LAS COMUNIDADES AUTÓNOMAS.}

\subsection{METOdOLOGÍA}

Los objetivos que nos marcamos con el uso de esta metodología son:

A) Conocer la información sobre rutas e itinerarios disponibles en la web para los usuarios; es el objetivo principal de la investigación de la metodología pretendiéndose la comprensión de la utilidad y estructuración de la información.

B) Constatar la oferta de rutas e itinerarios culturales; es el paso inicial que nos va a permitir realizar los siguientes análisis y verificar si las webs promocionan estos recursos.

C) Comprobar si se hace una distinción entre los conceptos de ruta e itinerarios. A lo largo del documento hemos estudiado las propuestas y diferencias entre ambos conceptos. Por lo tanto, llegados a este punto, resulta necesario comprender el tratamiento que hacen las CCAA en los portales sobre los términos, y si estos son presentados en función a sus diferencias o particularidades. 
Tabla 2. Muestras seleccionadas por CCAA, fecha de consulta y fuente.

\begin{tabular}{|c|c|c|}
\hline $\begin{array}{l}\text { Comunidad } \\
\text { autónoma }\end{array}$ & $\begin{array}{l}\text { Fecha de } \\
\text { Consulta }\end{array}$ & Fuente \\
\hline Andalucía & 20/01/2018. & http://www.andalucia.org/es/rutas/ \\
\hline Asturias & 20/01/2018. & $\begin{array}{l}\text { https://www.turismoasturias.es/descubre/naturaleza/rutas } \\
\text { https://www.turismoasturias.es/descubre/cultura/itinerarios- } \\
\text { culturales }\end{array}$ \\
\hline Aragón & 20/01/2018. & http://www.turismodearagon.com/es/rutas.html \\
\hline $\begin{array}{l}\text { Castilla la } \\
\text { Mancha }\end{array}$ & $20 / 01 / 2018$ & http://www.turismocastillalamancha.es/rutas/ \\
\hline Castilla y León & 19/01/2018. & $\begin{array}{l}\text { http://www.turismocastillayleon.com/es/arte-cultura- } \\
\text { patrimonio/rutas-culturales }\end{array}$ \\
\hline Cantabria & 20/01/2018. & http://turismodecantabria.com/rutas-por-cantabria \\
\hline Cataluña & 19/01/2018. & http://www.catalunya.com/que-fer/rutes-tematiques \\
\hline $\begin{array}{l}\text { Comunidad } \\
\text { Valenciana }\end{array}$ & 19/01/2018. & http://comunitatvalenciana.com/que-hacer/turismo-cultural \\
\hline Extremadura & 19/01/2018. & $\begin{array}{l}\text { http://www.turismoextremadura.com/viajar/turismo/es/explor } \\
\text { a/rutas/ }\end{array}$ \\
\hline Galicia & 19/01/2018. & http://www.turismo.gal/que-facer/rutas-turisticas?langld=es_ES \\
\hline Islas Baleares & 19/01/2018. & http://www.illesbalears.travel/es/baleares/rutas-y-planes \\
\hline Islas Canarias & 19/01/2018. & http://www.holaislascanarias.com/ \\
\hline La Rioja & $20 / 01 / 2018$ & $\begin{array}{l}\text { https://lariojaturismo.com/comunidad/larioja/ver-y- } \\
\text { hacer?default;rdf:type=attraction }\end{array}$ \\
\hline Madrid & 20/01/2018. & http://turismomadrid.es/es/buscador.html?q=rutas\&Search= \\
\hline Murcia & 19/01/2018. & https://www.murciaturistica.es/es/rutas/ \\
\hline Navarra & 20/01/2018. & $\begin{array}{l}\text { http://www.turismo.navarra.es/esp/mapa- } \\
\text { buscador/recursos.aspx?tipoBuscador=rt }\end{array}$ \\
\hline País Vasco & 20/01/2018. & https://turismo.euskadi.eus/es/rutas-planes/ \\
\hline
\end{tabular}

Fuente: Elaboración propia.

D) Ofrecer una tipología de rutas culturales. Se pretende conocer el tipo de rutas culturales existente, englobándolas en un modelo de clasificación explicado más adelante.

En el análisis que se llevará a cabo se va a emplear una metodología analítica, consistente en el estudio sistemático y estructurado de las páginas webs oficiales de turismo autonómico. El motivo que justifica la utilización en exclusiva de los portales oficiales en este análisis, es considerar el funcionamiento de una de las principales fuentes de información turística a nivel institucional (Fernández, Vinyals, López, 2013). La muestra seleccionada englobará a todas las CCAA, a excepción de las ciudades autónomas de Ceuta y Melilla (Tabla 2).

Para determinar las rutas, que, para nuestro estudio, pueden ser consideradas como culturales, se atenderá a dos criterios básicos. Por un lado, tendremos en cuenta aquellas rutas que según lo dispuesto por las CCAA tengan la clasificación de ruta cultural $y$, por otro lado, se analizarán aquellas rutas que pueden ser consideradas

Revista de Estudios Andaluces, núm. 35 (2018) pp. 123-145. e-ISSN: 2340-2776 http://dx.doi.org/10.12795/rea.2018.i35.05 
culturales, como es el caso de las etnográficas, gastronómicas, temáticas, enológicas y, en definitiva, todas aquellas que proponen la realización de actividades culturales 0 utilizan recursos culturales.

El modelo que proponemos de clasificación de rutas culturales reflejado en el cuadro 1 (Arcila, M. et al., 2015), ofrece la posibilidad de diferenciar las tipologías de rutas en función de sus características específicas. Para concretar las "rutas geográficas" podemos definirlas como aquellas que conectan un espacio geográfico que engloba recursos diferentes.

Cuadro 1. Modelo de clasificación de rutas.

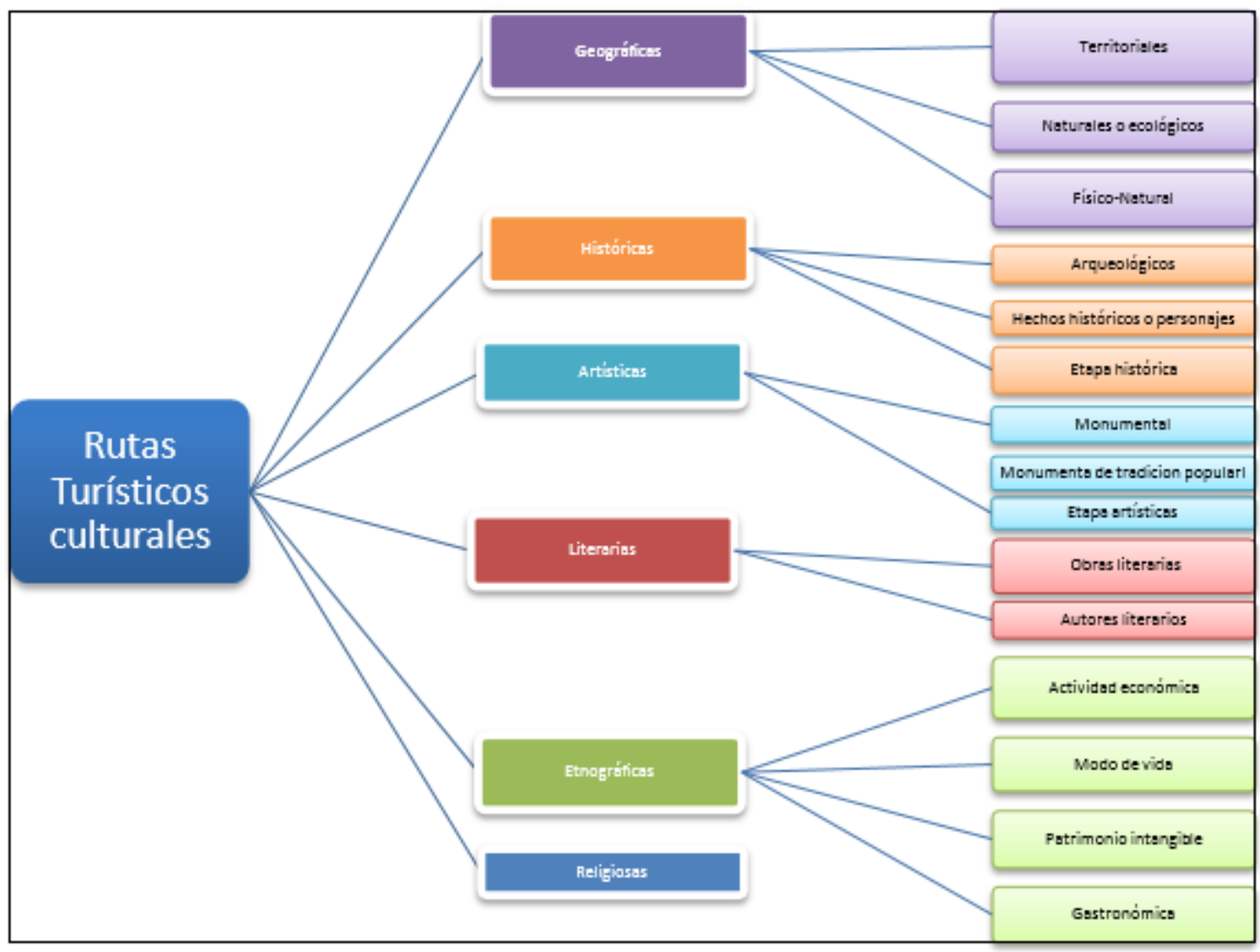

Fuente: Elaboración propia.

Por su parte, para verificar si las webs autonómicas distinguen conceptualmente las rutas e itinerarios, se procederá al análisis del uso que se hace de los mismos en los textos de las webs.

En lo que respecta a la existencia y difusión de itinerarios culturales europeos, se examinará el listado oficial de itinerarios europeos ${ }^{7}$ para luego, estudiar su constancia

${ }^{7}$ Información obtenida de la web del Consejo de Europa( https://www.coe.int/en/web/culturalroutes/spain) y contrastada en el portal oficial del Ministerio de Educación, Cultura y Deporte Revista de Estudios Andaluces, núm. 35 (2018) pp. 123-145. e-ISSN: 2340-2776 http://dx.doi.org/10.12795/rea.2018.i35.05

\section{(c) (i) (8)}


y promoción en las webs autonómicas y si estos recursos se utilizan como un valor añadido.

Por último, se va a identificar la información comercial existente estructurándola en función de su nivel de detalle. En la comprobación tendremos en cuenta la oferta de servicios de hostelería, ocio, cultura y transportes.

\subsection{RESULTADOS Y DISCUSIÓN}

De la aplicación de la metodología antes expuesta, en todas las páginas web de los portales de turismo de las Comunidades Autónomas, se han obtenido una serie de resultados que se expondrán en las siguientes páginas y que pueden resumirse en el gráfico 1.

Como se puede observar los itinerarios y las rutas turísticas consideradas culturales son un elemento fundamental en la oferta turística oficial de todas las comunidades autónomas. El auge de la oferta cultural dentro del sector se entiende siguiendo a Toselli (2006) por el interés por la valoración de la cultura, el deseo de otorgar un valor añadido a la oferta turística, desestacionalizar el sector, potenciar el desarrollo a escala local, fortalecer políticas culturales, recuperar recursos patrimoniales y promover la comprensión y el entendimiento entre los pueblos. Este hecho se pone de manifiesto en un contexto de globalización del mercado $y$, por lo tanto, en la necesidad de potenciar los atractivos singulares de los destinos (Filardo, 2006), sobre todo a escala local. Hay que insistir en la idea de la imposibilidad de deslocalización de los recursos patrimoniales, por lo que este tipo de oferta es imprescindible que se desarrolle en los territorios en donde se generan.

Una de las características más palpables de los resultados del análisis de la oferta turístico-cultural es la confusión existente entre los conceptos de rutas e itinerarios culturales, salvo excepciones como en el caso de Galicia, Asturias y Navarra (un 17,6 \% del total de la muestra). Por un lado, algunas CCAA publicitan los itinerarios como si fueran rutas, mientras que por otro lado llaman itinerarios a los recorridos o trazados de las rutas turísticas. De este modo se observa que esta confusión la podemos abordar desde el punto de vista filológico, ya que los conceptos de ruta e itinerario se tratan como sinónimos. Esto provoca que el objetivo de promoción cultural y turística que las instituciones se marcan con la declaración e institucionalización de estos instrumentos, no se alcance satisfactoriamente. Por otra parte, debemos tener en cuenta que, mientras que algunos itinerarios son de reciente creación (Ruta de los Cementerios o la Ruta de los Fenicios) y tienen un carácter instrumental, otros están consolidados y cuentan con un trazado histórico propio (Camino de Santiago o la Vía de la Plata).

https://www.mecd.gob.es/cultura/areas/patrimonio/mc/patrimonio-consejo-europa/itinerarios /presentacion.html

Revista de Estudios Andaluces, núm. 35 (2018) pp. 123-145. e-ISSN: 2340-2776 http://dx.doi.org/10.12795/rea.2018.i35.05 (c) (i) (8) 
Gráfico 1. Rutas e Itinerarios turístico culturales en las webs de las CCAA.

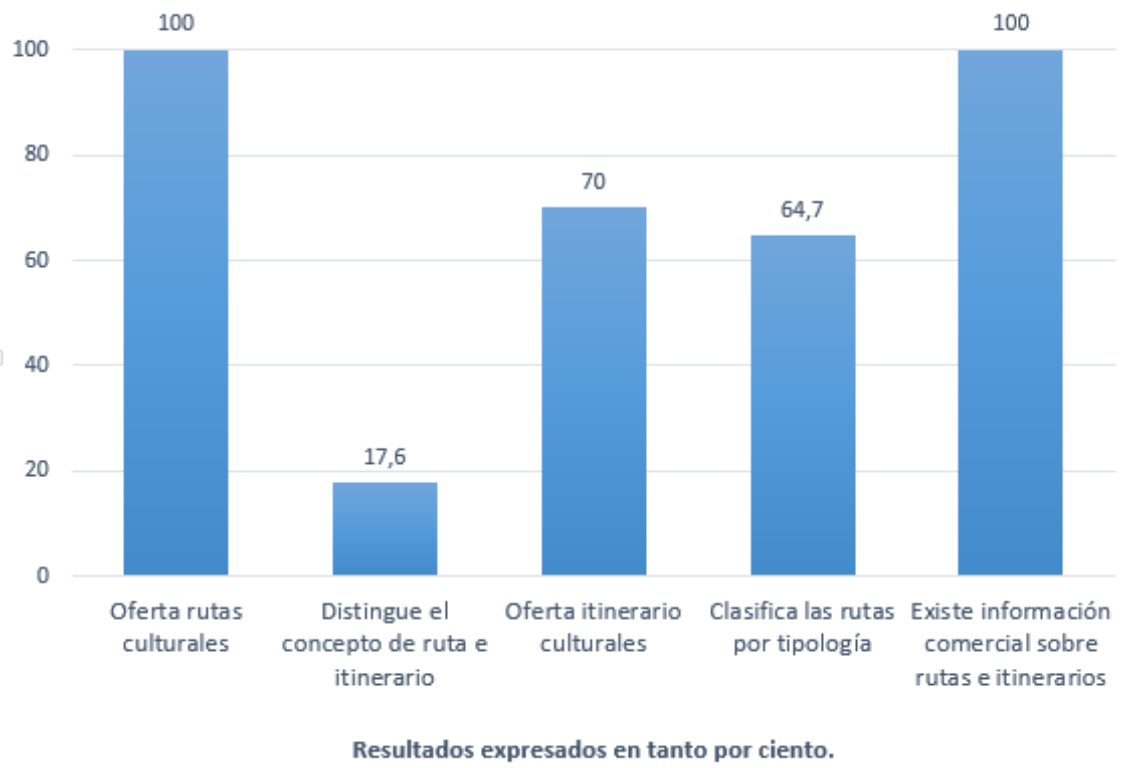

Fuente: Elaboración propia a partir del análisis de las webs oficiales de turismo autonómico.

De la comparativa entre los itinerarios culturales europeos existentes en España y de los promocionados en las webs oficiales autonómicas hemos concluido los resultados de los mapas ${ }^{8} 1$ y 2 . El análisis efectuado pone de manifiesto que la oferta de itinerarios culturales europeos se realiza en 13 de la 15 CCAA (un 86,6\% de la muestra). No obstante, los resultados dejan ver que tan sólo 3 de los 22 itinerarios culturales europeos declarados en España (Camino de Santiago, Ruta de Carlos V y El Legado Andalusí), están presentes en los portales oficiales. Debemos tener en cuenta que, mientras que algunos itinerarios son de reciente creación (Ruta de los Cementerios o la Ruta de los Fenicios) y tienen un carácter instrumental, otros están consolidados y cuentan con un trazado histórico propio (Camino de Santiago o la Vía de la Plata). Por lo tanto, la presencia en la web atiende más a las posibilidades turísticas de los itinerarios que al carácter cultural de los mismos.

El camino de Santiago ocupa un papel predominante, apareciendo en todas las comunidades por las que discurre a excepción de Andalucía y Extremadura. Ello demuestra la relevancia que ha adquirido dicho itinerario a nivel nacional y europeo, con la condición de gran itinerario cultural concedida en 2004 y el Premio Príncipe de Asturias a la Concordia ese mismo año. Por otro lado, se ha consolidado su demanda como producto turístico ampliándose su oferta en mercados como EEUU y Australia (Santos, 2006).

\footnotetext{
${ }^{8}$ Se excluyen las Islas Canarias y las Islas Baleares, ya que no hay itinerarios culturales declarados en estos territorios.

Revista de Estudios Andaluces, núm. 35 (2018) pp. 123-145. e-ISSN: 2340-2776

http://dx.doi.org/10.12795/rea.2018.i35.05
} c) $($ ) $(9)$ 
Mapa 1. Distribución de los itinerarios culturales europeos declarados por CCAA.

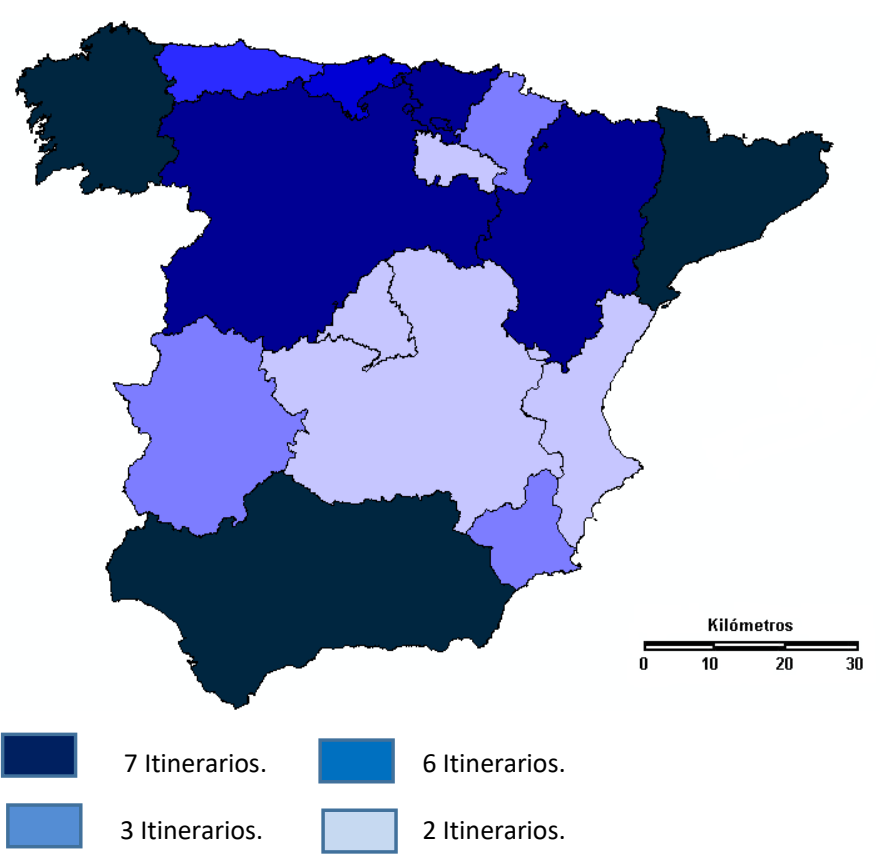

Fuente: Elaboración propia.

Mapa 2. Número de Itinerarios Culturales europeos promocionados en las webs.

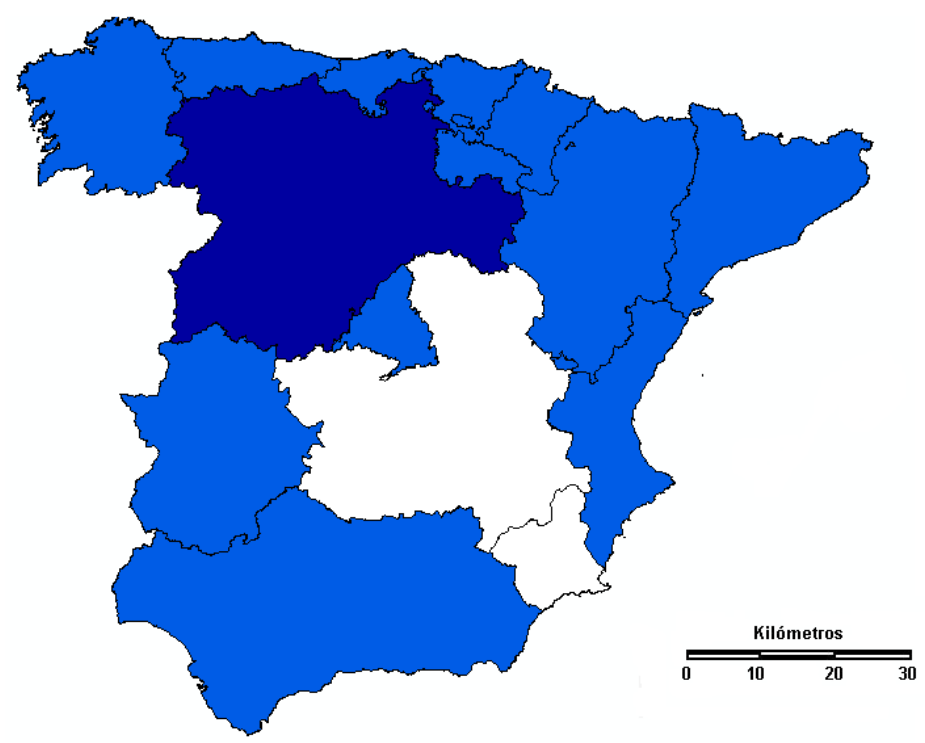

Promociona 2 Itinerarios culturales.

Promociona 1 Itinerario Cultural. No promociona Itinerarios Culturales.

Fuente: Elaboración propia.

Revista de Estudios Andaluces, núm. 35 (2018) pp. 123-145. e-ISSN: 2340-2776 http://dx.doi.org/10.12795/rea.2018.i35.05

\section{(c) (1) $\$$}


Debemos mencionar, además, que el tratamiento de los conceptos de ruta e itinerarios como conceptos sinónimos, afecta a la propia difusión de los itinerarios ya que, desde las instituciones, no se presentan al turista como un recurso diferente al de las rutas. Las referencias a los itinerarios se basan principalmente en su reconocimiento internacional, con pocas referencias al trazado como elemento patrimonial en sí.

Es interesante hacer alusión a las clasificaciones de las rutas turísticas que hacen las páginas institucionales y la forma de organización para su consulta. De este modo, mientras que en algunas comunidades no se hace una clasificación exhaustiva de las rutas (Castilla la Mancha, Extremadura, Galicia, Comunidad Valenciana y las Islas Canarias), otras proponen su propia clasificación (Andalucía, Cataluña, País Vasco o Baleares). En general se puede afirmar que no hay una clasificación estandarizada de los diferentes tipos de ruta y, por lo tanto, cada autor o institución elabora su propia clasificación (Arcila, M et al., 2015), sin tener presentes las conceptualizaciones ofrecidas por los diferentes organismos internacionales sobre esta materia. En la clasificación persiste en muchos casos, la confusión entre rutas e itinerarios, ya que es bastante frecuente que, en los apartados de rutas, aparezcan tanto rutas como itinerarios culturales como si fueran una misma categoría.

Por su parte, en un intento por conocer el tipo de rutas turístico culturales existentes en cada CCAA, hemos cruzado las clasificaciones de rutas promocionadas en las webs con el modelo de rutas propuesto anteriormente. Los resultados han sido resumidos en la tabla 3. Las rutas geográficas son las más abundantes (un total del $76,4 \%$ de la muestra) seguidas de las rutas etnográficas $(52,9 \%)$, las artísticas $(29,4 \%)$ y las religiosas (23,5\%). Las restantes tipologías obtienen un discreto porcentaje. Del análisis realizado se pone de manifiesto que, al comparar las tipologías de rutas de las CCAA y un modelo propuesto, la realidad difiere de la teoría. En este sentido se debe indicar que, si el estudio se realizara atendiendo a las rutas existentes dejando al margen las tipologías, los resultados serían diferentes y se podrían incluir a aquellas comunidades que no ofrecen tipologías de rutas.

Además, debemos tener en cuenta que, desde el punto de vista de la ordenación y presentación de la información de la oferta turística en las diferentes webs oficiales, se puede afirmar que la misma no es homogénea. Por lo tanto, los usuarios que se aproximen a buscar información sobre turismo cultural y concretamente sobre rutas e itinerarios culturales encontraran una búsqueda más sencilla en comunidades donde se estructuran las rutas e itinerarios por apartado y tipología (País Vasco o Andalucía) que en otras donde no se clasifican las rutas o bien su localización es confusa (Cantabria).

Por último, se debe destacar que todas las páginas institucionales de turismo promocionan la venta directa de alojamientos, hostelería y recursos turísticos, así como proporcionan información de las rutas. Ello demuestra la importancia del

Revista de Estudios Andaluces, núm. 35 (2018) pp. 123-145. e-ISSN: 2340-2776 http://dx.doi.org/10.12795/rea.2018.i35.05 
Tabla 3. Propuesta de tipologías de rutas en las CCAA.

\begin{tabular}{|c|l|l|l|l|l|l|}
\hline $\begin{array}{c}\text { Comunidad } \\
\text { Autónoma }\end{array}$ & Geográficas & Históricas & Artísticas & Literarias & Etnográficas & Religiosas \\
\hline Andalucía & & & & & & \\
\hline Asturias & & & & & & \\
\hline Aragón & & & & & & \\
\hline $\begin{array}{c}\text { Castilla la } \\
\text { Mancha }\end{array}$ & & & & & & \\
\hline Castilla y León & & & & & & \\
\hline Cataluña & & & & & & \\
\hline $\begin{array}{c}\text { Comunidad } \\
\text { Valenciana }\end{array}$ & & & & & & \\
\hline Cantabria & & & & & & \\
\hline Extremadura & & & & & & \\
\hline Galicia & & & & & & \\
\hline Islas Baleares & & & & & & \\
\hline Islas Canarias & & & & & & \\
\hline La Rioja & & & & & & \\
\hline Madrid & & & & & & \\
\hline Murcia & & & & & & \\
\hline Navarra & & & & & & \\
\hline País Vasco & & & & & & \\
\hline
\end{tabular}

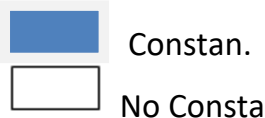

Fuente: Elaboración propia.

turismo como sector económico estratégico y los deseos de los gobiernos autonómicos de promocionarse como destinos turísticos (Rengifo, 2006).

\section{CONCLUSIÓN}

En términos generales se puede afirmar que el interés existente por la definición y diferenciación de los conceptos de rutas e itinerarios culturales se explica por la demanda de los mismos como productos turísticos. Esta proliferación de rutas e itinerarios se justifica en la necesidad de diversificación de la oferta turística y los beneficios del turismo cultural para el sector. Estas ventajas se resumen en desestacionalización de la demanda, perfil socio económico elevado de los usuarios, impulso de la economía local sostenible y su bajo impacto ambiental. Además, en muchos casos, el deseo de favorecer la existencia de estos productos ha facilitado la colaboración entre los ciudadanos y las instituciones (Briedenhann y Wikens, 2003). Por otro lado, el auge de las rutas culturales ha generado un cambio en la percepción del patrimonio, entendiéndose como una herramienta de desarrollo territorial, propiciando su conservación y puesta en valor (Capel, 2005). De igual forma los ciudadanos y residentes en esos espacios, mejoran su visión del patrimonio con esta puesta en valor.

Revista de Estudios Andaluces, núm. 35 (2018) pp. 123-145. e-ISSN: 2340-2776 http://dx.doi.org/10.12795/rea.2018.i35.05

$$
\text { (c) (i) (8) }
$$


Al estudiar el concepto de ruta, debemos tener en cuenta que no se presenta con un carácter uniforme porque la definición depende de los objetivos, el diseño, la temática o la metodología aplicada en la creación de la ruta (Rivera, 2016). Este último aspecto explica que, en muchas ocasiones, las rutas turísticas diseñadas no utilicen una metodología contrastada y que carezcan de base teórica. En lo que respecta a los itinerarios culturales, entendemos que son realidades diferentes a las rutas por su origen y configuración. Cada organismo internacional que se ha preocupado por este tema propone su marco teórico, así cada institución hace hincapié en un aspecto concreto, como puede ser el carácter europeo (Consejo de Europa) o la importancia de los recorridos (ICOMOS). Aunque en el ámbito académico e institucional los términos de ruta e itinerario cultural estén claramente definidos, en la práctica existe una notable confusión en su uso por los organismos turísticos. Este error se detecta en la difusión no diferenciada de estos productos turísticos sin tener en cuenta los elementos singulares de cada uno de ellos.

Del estudio sobre las rutas e itinerarios culturales ofertados en las CCAA se pueden concluir algunos aspectos destacables. A pesar del indudable interés de las CCAA por ofertar rutas turísticas, se detectan algunas áreas de evidente mejora, ya que el fin de la gestión del patrimonio territorial es la ordenación del territorio (Doctor, 2011). En primer lugar, existe una falta de sistematización y homogeneización de la oferta de rutas e itinerarios en las CCAA. En algunos casos la oferta difundida es deficiente no adecuándose a la realidad patrimonial y cultural de los territorios. Por lo tanto, sería necesaria una reestructuración de la oferta que mejore el conocimiento de las rutas turísticas e itinerarios que existen en el territorio.

En segundo lugar, resulta especialmente llamativo el escaso uso que se está haciendo de los itinerarios culturales europeos salvo algunas excepciones (Camino de Santiago). Aunque los itinerarios no tienen una finalidad exclusivamente turística, son un elemento representativo de la cultura de las regiones $\mathrm{y}$, por consiguiente, un instrumento que puede facilitar la diferenciación en el mercado de los destinos. Por ello se considera que, la oferta de los itinerarios culturales debería realizarse como una categoría independiente a las rutas resaltándose el valor patrimonial del camino y su importancia cultural. Además, en la redacción de los textos es necesaria una revisión que no contemple la confusión terminológica referida en párrafos anteriores.

En tercer lugar, se considera necesario la existencia de una clasificación tipológica de rutas en los portales autonómicos. La razón no es otra que el establecimiento de criterios que permitan una navegación más sencilla. Además, la presentación de las mismas es en algunos casos incompleta, ya que falta información detallada que incluya algunos datos básicos de las rutas.

Se puede concluir que a pesar del uso confuso de los conceptos por parte de las CCAA y de algunas debilidades detectadas en el análisis, se observa que el avance del turismocultural y, por ende, de las rutas e itinerarios, es constante. No obstante,

Revista de Estudios Andaluces, núm. 35 (2018) pp. 123-145. e-ISSN: 2340-2776

http://dx.doi.org/10.12795/rea.2018.i35.05

(c) (i) (3) Esta obra se distribuye con la licencia Creative Commons Reconocimiento-NoComercialSinObraDerivada 4.0 Internacional 
desde el punto de vista de los usuarios turísticos es necesario presentarles estos productos en base a sus elementos diferenciadores (Yepes, 2000), en aras de promover su puesta en valor y su uso turístico, mejorando y homogeneizando la terminología utilizada, para no crear confusión entre los usuarios de las rutas e itinerarios turístico culturales.

\section{BIBLIOGRAFÍA}

Arcila, M., López, J. A., Fernández Enríquez, A. (2015). Rutas turístico-culturales e itinerarios culturales como productos turísticos: reflexiones sobre una metodología para su diseño y evaluación. XXIV Congreso de la Asociación de geógrafos españoles. Universidad de Zaragoza. (En línea).< http://congresoage.unizar.es/eBook/trabajos /049_Arcila\%20Garrido.pdf >.

Briedenhann, J., Wikens, E. (2003). Tourism routes as a tool for the economic development of rural areas. Vibrant hope or imposible dream?" Tourism Management, 57, 1-9.

Castillo, J. (2006). Los itinerarios culturales. Características y tipos. Principales experiencias nacionales e internacionales. Cuadernos de Arte de la Universidad de Granada, 37, 319-335.

Carrera Díaz, G. (2006). Itinerarios y rutas: herramientas para la documentación y puesta en valor del patrimonio cultural. Boletín del Instituto Andaluz del Patrimonio Histórico l, 60, 52-59. (En línea)

http://www.iaph.es/revistaph/index.php/revistaph/articlem/view/2256\#.WIJgVkxFzIU.

Capel, H. (2005). Las rutas culturales como patrimonio de la Humanidad. El caso de las fortificaciones americanas del Pacífico. Biblio 3W. Revista Bibliográfica de Geografía y Ciencias Sociales, X (562), 1-25. (En línea).

< http://www.ub.edu/geocrit/b3w-562.htm >

Capp, S. (2001). The European Institute of Cultural Routes. Recuperado de www.arcchip.cz/w02/w02_capp.pdf.

Consejo de Europa. (2002). Programa de los itinerarios culturales del Consejo de Europa. Luxemburgo.

Correyero Ruiz, B. (2001). Las rutas de la guerra y los periodistas portugueses. Historia y Comunicación Social, 6, 123-134. (En línea).

<http://revistas.ucm.es/index.php /HICS/article/view/HICS0101110123A >

Revista de Estudios Andaluces, núm. 35 (2018) pp. 123-145. e-ISSN: 2340-2776

http://dx.doi.org/10.12795/rea.2018.i35.05

(c) (1) (2) Es 
Correyero, B., Cal, R. (2008). Turismo: La mayor propaganda de estado. España: desde sus inicios hasta 1951. Madrid: Visionnet.

Doctor, A (2011). El itinerario como herramientas para la puesta en valor turístico del patrimonio territorial. Cuadernos de Turismo, 27, 273-289. (En línea).

<http://revistas.um.es/turismo/article/view/139951/125851>

Filardo, V. (2006). Globalización y turismo: impactos en los territorios. Pampa, Revista Interuniversitaria de Estudios Territoriales, 2, 185-21. (En línea).

<http://www.bibliotecavirtual.unl.edu.ar/ojs/index.php/PAMPA/article/view/3136>

Fernández Cavía, J., Vinyals Mirabent, S., López Pérez, M. (2013). Calidad de los sitios web turísticos oficiales de las comunidades autónomas españolas. BiD: textos universitaris de biblioteconomia i documentació, 31. (En línea).

<http://bid.ub.edu/es/31/fernandez2.htm>

García, L., González, J. (2001). Breves anotaciones sobre el concepto de cultura en el mundo clásico. Actas de las III jornadas de Humanidades Clásicas Almendralejo. (En línea). <https://dialnet.unirioja.es/servlet/articulo?codigo=2676951>

Gómez Prieto, J. y Quijano Díaz, C. (1991). Rutas e itinerarios turísticos en España. Madrid: Síntesis.

Hernández Ramírez, J. (2011). Los caminos del patrimonio. Rutas turísticas e itinerarios culturales. Revista Pasos Vol. 9 № 2, 225-236. (En línea). < http://www.pasosonline.org /Publicados/9211/PS0211_01.pdf >

ICOMOS. (1976). Carta de ICOMOS. Bruselas.

ICOMOS. (1999). Carta Internacional sobre Turismo Cultural.

ICOMOS. (2008). Carta de Itinerarios Culturales, 16a AG. Québec (Canadá), 4 de octubre.

López Fernández, M, I. (2006). Diseño y programación de itinerarios culturales. Boletín del Instituto Andaluz de Patrimonio Histórico, no60, noviembre 2006, 23-30. (En línea). < http://www.iaph.es/revistaph/index.php/revistaph/article/view/2253\#.WIJitExFzIU >

Martorell Carreño, A. (2003). Cultural routes: Tangible and intangible dimensions of cultural heritage. ICOMOS sicentific symposium: Place-memory-meaning: preserving intagible values in monuments and sites, 45-51.

Martorell Carreño, A. (2017). Criterios de comparación entre itinerarios culturales (patrimoniales) y rutas diseñadas. Turismo y patrimonio, [S.I.], n. 8, 103-114, ago. 2017.

Revista de Estudios Andaluces, núm. 35 (2018) pp. 123-145. e-ISSN: 2340-2776 http://dx.doi.org/10.12795/rea.2018.i35.05 
(En línea). <http://ojs.revistaturismoypatrimonio.com/index.php/typ/article/view/53>

Ministerio de Educación y Ciencia. (2015). Programa de los Itinerarios Culturales del Consejo de Europa. Recuperado de https://www.mecd.gob.es/dam/jcr:590c8c170eb5-48ba-b47f-5d42b5206dbd/itinerarios-culturales.pdf ( 2 de Enero de 2018).

Morère Molinero, N. (2012). Sobre itinerarios culturales del ICOMOS y las rutas temáticas turístico-culturales. Una reflexión sobre su integración en turismo. En Revista de Análisis Turístico, no13, 1ำ semestre 2012, 57-68. (En línea). <http://www.aecit.org/jornal/index.php/AECIT/article/view/122>

Moreno Garrido, A. (2007). Historia del turismo en España en el siglo XX. Síntesis, Madrid.

MERCOSUR. (2009). Anteproyecto de itinerarios culturales del Mercosur. San Salvador Bahía. Brasil.

Navalón García, R. (2014), Rubio, L., Ponce, G.: Escenarios, imaginarios y gestión del patrimonio. Ed. Serv. Public Univ Autónoma Metropolitana -Xochimilco (Mexico) y Universidad de Alicante (España). (En línea). <https://rua.ua.es/dspace/bitstream/ 10045/48846/1/Creacion-de-rutas-Navalon-2014.pdf >

OTM. (2005). El turismo urbano y la cultura- La experiencia europea. Madrid, OTM.

Oxford University Press. (2008). Gran diccionario OXFORD Español-inglés, inglésespañol. 4ํㅡㄹición. Oxford University Press.

Orduña, G., Urpí, C. (2010). Turismo cultural como experiencia educativa de ocio. Polis Revista Latinoamericana no 26, 34-55. (En línea). <http://journals.openedition.org/polis/102>

Parrado del Olmo, J. (2003). "Planteamientos generales. Rutas culturales activas. La cultura como elemento de la Unión Europea". La cultura como elemento de unión en Europa. Rutas culturales activas, 17- 29.

Parada Vázquez, R. (2013). Derecho Administrativo tomo III. Open Ediciones.

Pulido Fernández, J.L. (2013). Turismo cultural. Síntesis.

Pulido Fernández, J.L. (2006). ¿Por qué no funcionan turísticamente algunos itinerarios o rutas culturales? Boletín del Instituto Andaluz de Patrimonio Histórico, $n$ o60, noviembre 2006, 10-14. (En línea).<http://www.iaph.es/revistaph/index.php /revistaph/article/view/2262\#.WIJkaUxFzIU> 
Real Academia de la Lengua Española. (2014). Diccionario de la lengua española. 23ạ Edición. Espasa. Madrid.

Rengifo, J. (2006). Rutas culturales y turismo en el contexto español. PH. Boletín del Instituto Andaluz del Patrimonio Histórico, no 60, 114-125. (En línea). <http://www.iaph.es/revistaph/index.php/revistaph/article/view/2263\#.WIJkrExFzIU>

Rivera Mateos, M. (2016). Rutas turístico-culturales responsables y desarrollo local: La experiencia piloto de la "Ruta de la Córdoba de las américas". Huelva: Diputación de Huelva.

Santos Solla, X. (2006). El Camino de Santiago: turistas y peregrinos hacia Compostela. Cuadernos de Turismo, no18, 135-159. (En línea) <http://www.redalyc.org /pdf/398/39801805.pdf >

Senabre López, D. (2006). La adjetivación "cultural" como atributo adulterado del nuevo ocio teledirigido. Boletín del Instituto Andaluz del Patrimonio Histórico no60, 130-141. (En línea).<http://www.iaph.es/revistaph/index.php/revistapharticle/view /2265\#.WIJIRkxFzIU>

Tresserras J.J. (2003). Patrimonio, turismo, y desarrollo local: situación y perspectivas. Análisis Sectoriales: Estudio compartido sobre turismo y cultura. Portal Iberoamericano de Gestión Cultural.

Tresserras J.J. (2001). Gestión del patrimonio cultural. Barcelona: Ariel.

Tresserras, J. (2006). Rutas e itinerarios culturales en Iberoamérica. Cuadernos de Patrimonio Cultural y Turismo, 13-50.

Tendré, F. (2007). El patrimonio cultural y los itinerarios culturales del Consejo de Europa: Nuevas orientaciones. Recuperado de http://www.redjuderias.org /red/upload/boletin/pdf/BO-08-281.pdf

Tondre, F. (2007). El Patrimonio Cultural y los Itinerarios Culturales del Consejo de Europa: nuevas orientaciones, caminos hacia la diversidad, puentes entre las comunidades. AA. VV Caminos de Sefarad. Memoria 2007 (28-34). Jaén: Red de juderías de España. (En línea). < https://www.mecd.gob.es/dam/jcr:94ba4e8f-cf3b4f7b-ad0d-7e0a7986dcee/patrimonio-itinerariosce.pdf >

Torres Bernier, E. (2006). Rutas culturales. Recurso, destino y producto turístico. Boletín del instituto Andaluz del Patrimonio Histórico I n60, 84-97. (En línea). $<$ http://www.

iaph.es/revistaph/index.php/revistaph/article/view/2259\#.WIJmM0xFzIU > 
VVAA. (2010). Patrimonio e innovación. Patrimonio Cultural de España no4. Ministerio de Cultura.

Vidargas, F., López Morales, F.J. (2011). Itinerarios culturales: planes de manejo y turismo sustentable. Conference volumen. Instituto Nacional de Antropología e Historia.México. (En línea).<http:// openarchive.icomos.org/1032/1/Itinerarios_Culturales_\%282011\%29.pdf >

Yepes Piqueras, V. (2000). Los itinerarios temáticos como elementos diferenciadores del producto turístico global. Actas del $V$ congreso Internacional de Caminería hispánica 17-22 Julio 2000. 